\title{
PD-L1 and PD-1 expression correlate with prognosis in extrahepatic cholangiocarcinoma
}

\author{
$\mathrm{KE} \mathrm{MA}^{1 *}, \mathrm{XIN} \mathrm{WEI}^{2 *}, \mathrm{DANFENG} \mathrm{DONG}^{1}, \mathrm{YINYING} \mathrm{WU}^{1}, \mathrm{QIANQIAN} \mathrm{GENG}^{1}$ and ENXIAO LI ${ }^{1}$ \\ ${ }^{1}$ Department of Medical Oncology, The First Affiliated Hospital of Xi'an Jiaotong University, Xi'an, \\ Shaanxi 710061; ${ }^{2}$ Department of Medical Oncology, Shaanxi Province People's Hospital, Xi'an, Shaanxi 710068, P.R. China
}

Received September 12, 2015; Accepted February 17, 2017

DOI: $10.3892 / \mathrm{ol} .2017 .6105$

\begin{abstract}
The present study aimed to investigate the clinicopathological significance of programmed cell death ligand-1 (PD-L1) and programmed cell death protein 1 (PD-1) expression in extrahepatic cholangiocarcinoma (ECC). PD-L1 and PD-1 expression was detected by immunohistochemical methods in 70 ECC formalin-fixed, paraffin-embedded tissue specimens and 50 para-carcinoma tissue specimens. The associations of PD-L1 and PD-1 expression with clinicopathological characteristics and prognosis of ECC patients were explored. Positive rates of PD-L1 and PD-1 expression were increased in ECC tissues compared with those in the corresponding para-carcinoma tissues. Besides, the expression of PD-L1 was correlated with the expression of PD-1 $(\mathrm{P}<0.05)$. Statistical analysis revealed that the expression of PD-L1 and PD-1 in ECC tissues exhibited no correlation with patient age, sex or histological grade, but was significantly correlated with tumor-node-metastasis (TNM) stage and lymphatic metastasis. Univariate analysis demonstrated that PD-L1 expression, PD-1 expression, TNM stage and lymphatic metastasis were significantly associated with the survival time of patients. Further multivariate analysis revealed the PD-L1 expression was an independent prognostic factor of patients with ECC. These preliminary results suggested that PD-L1 or PD-1 immunodetection may be a valuable prognostic marker for ECC patients, and that PD-L1 immunodetection may be used as an independent factor to evaluate the prognosis of ECC patients.
\end{abstract}

Correspondence to: Dr Enxiao Li, Department of Medical Oncology, The First Affiliated Hospital of Xi'an Jiaotong University, 277 Yanta West Road, Xi'an, Shaanxi 710061, P.R. China

E-mail: doclienxiao@sina.com

*Contributed equally

Abbreviations: PD-L1, programmed cell death ligand-1; PD-1, programmed cell death protein 1

Key words: extrahepatic cholangiocarcinoma, PD-L1, PD-1, immunohistochemistry, survival analysis, prognosis

\section{Introduction}

Extrahepatic cholangiocarcinoma (ECC) is a type of primary malignancy with a poor prognosis originating from extrahepatic biliary epithelial cells $(1,2)$. At present, there is no effective therapy other than surgical resection for ECC. Furthermore, despite having received complete tumor resection, the majority of ECC patients still develop local recurrence or distant metastasis (3). Therefore, novel approaches to treat ECC are urgently required in order to improve patient prognosis.

With the further understanding of the regulation of the immune system and the development of immunotherapies, immune checkpoint blockade has emerged as one of the most promising strategies for treating solid tumors $(4,5)$. Programmed cell death ligand-1 (PD-L1, also known as B7 homolog 1) is a member of the B7 family of molecules that is expressed on the surface of malignant cells in numerous tumor and tumor-associated antigen-presenting cells, and facilitates immune evasion via its interaction with programmed cell death protein 1 (PD-1) (6-9). High PD-L1 expression has been detected in a number of human malignancies, including gastric cancer (10), breast cancer (11), ovarian carcinomas (12), malignant melanoma (13), renal cell carcinomas (14), pancreatic carcinomas $(15,16)$, urothelial carcinomas (17-19), non-small cell lung cancer (20), intrahepatic cholangiocarcinoma (ICC) (21) and esophageal cancer (22). The PD-1 receptor is expressed on the surface of activated T cells and overexpressed in a large proportion of tumor-infiltrating lymphocytes (TILs) from various tumors, and leads to an intracellular inhibitory signal when bound to one of its ligands, namely PD-L1 (8,23-26).

Multiple tumors have been shown to express PD-L1 and PD-1 as a mechanism to achieve tumor immune evasion and immunotolerance (27-29); thus, it can be hypothesized that by blocking the binding of PD-1 to PD-1, activated T cells will retain the capacity for tumor surveillance and targeted destruction. Targeting the immune checkpoint can boost the anticancer responses of $\mathrm{T}$ cells and restore their ability to detect and attack cancer cells (30). This rationale has been clinically validated by a novel class of immunotherapeutic agents called checkpoint inhibitors, which include agents that target PD-1 and PD-L1 $(31,32)$.

With the aim of exploring the feasibility of ECC immunotherapy and understanding the prognosis of PD-1 and PD-L1 
expression in EEC patients, which has not been reported previously, the present study firstly detected the expression of PD-L1 and PD-1 in ECC patients, and analyzed the association of PD-L1 and PD-1 expression with clinicopathological characteristics and prognosis in ECC patients.

\section{Materials and methods}

Collection of clinical samples. Clinical data, including age, sex, tumor-node-metastasis (TNM) stage and pathological results, were retrospectively collected from 70 patients who underwent surgical resection and were pathologically confirmed to have ECC from February 2009 to March 2013 at the First Affiliated Hospital of Xi'an Jiaotong University (Xi'an, China). The group included 38 males and 32 females aged between 33 and 83 years (mean age, 62.5 years). Patients with ICC and/or ampullary carcinoma, or with other organ primary malignant tumors were excluded from the study. All the patients were staged according to the TNM stage classification system of the 2010 American Joint Committee on Cancer (AJCC) staging criteria (33). Survival time was calculated from the date of diagnosis to the end of follow-up. The patients were followed up until mortality or until the deadline date of the study (March 2015), and those whose information was incomplete were not included in the analysis. The present study was approved by the Ethics Committee of the First Affiliated Hospital of Xi'an Jiaotong University and written informed consent was obtained from all patients.

Immunohistochemical staining and scoring. All tissue specimens were formalin fixed, paraffin embedded and cut in 4- $\mu \mathrm{m}$-thick serial sections. Besides, 50 para-carcinoma tissues were assessed as the control group. To detect the expression of PD-L1 and PD-1, immunohistochemical staining was performed using an immunohistochemical kit (SP-9001; Beijing Zhongshan Golden Bridge Biotechnology Co., Ltd., Beijing, China) according to the manufacturer's protocol. Briefly, sections were dried for $30 \mathrm{~min}$ at $60^{\circ} \mathrm{C}$ prior to being deparaffinized in xylene and rehydrated through a series of graded ethanol solutions. Antigen retrieval was performed in $10 \mathrm{mM}$ citrate buffer $\left(\mathrm{pH} \mathrm{6.0)}\right.$ at $95^{\circ} \mathrm{C}$ for $5 \mathrm{~min}$. Then, the sections were treated with $3 \%$ hydrogen peroxide in methanol for $10 \mathrm{~min}$ at room temperature to quench endogenous peroxidase activity, which was followed by incubation with reagent $\mathrm{A}$ from the IHC kit for $15 \mathrm{~min}$ at room temperature. Subsequently, the sections were incubated with rabbit monoclonal anti-PD-L1 antibody (ab174838; Abcam, Cambridge, MA, USA ) at 1:250 dilution and rabbit monoclonal anti-PD-1 antibody (ab137132; Abcam) at 1:200 dilution in a humidified chamber at $4^{\circ} \mathrm{C}$ overnight. Upon being washed in PBS, the sections were sequentially incubated with reagents $\mathrm{B}$ and $\mathrm{C}$ for $15 \mathrm{~min}$ at $37^{\circ} \mathrm{C}$. Then, the sections were visualized by adding 3,3'-diaminobenzidine (ZLI-9018; Beijing Zhongshan Golden Bridge Biotechnology Co., Ltd.) according to the manufacturer's protocol. Finally, the sections were rinsed with water and counterstained with Harris hematoxylin. For the negative control, PBS was used instead of the primary antibody.

The staining results were scored with regard to the percentage of positive tumor cells and the intensity of overall staining. The sections were observed and independently scored by two pathologists. The judgment standards were as follows: i) PD-L1-positive result criterion in cancer cells: The proportion of stained cells in each field was assessed as $0,<5 \%$ stained cells; $1,5-25 \%$ stained cells; 2, 26-50\% stained cells; and $3,>50 \%$ stained cells. Staining intensity was graded as 0 , negative staining; 1 , weak staining; 2 , moderate staining; and 3 , intense staining. The staining-intensity-distribution (SID), which was obtained by multiplying the score of the percentage of stained cells by the score of the staining intensity, was judged as $0-2$ for negative staining and $\geq 3$ for positive staining; ii) PD-L1-positive result criterion in TILs: Negative, $<1 \%$ stained cells; and positive $\geq 1 \%$ stained cells (34); and iii) PD-1-positive result criterion in TILs: Five randomly selected different high-power fields were observed. The number of TILs in 300 lymphocytes in each field was counted. The mean number, i.e., 40 of the 70 specimens was considered as the threshold. If TIL $>40$, the staining was considered positive; if TIL $\leq 40$, the staining was considered negative.

Statistical analysis. Statistical analysis was performed using SPSS version 18.0 (SPPS, Inc., Chicago, IL, USA). Differences between two groups of measurement data were analyzed using the Student's t-test. The $\chi^{2}$ test was used to analyze the differences between groups of enumeration data. Kaplan-Meier plots and log-rank tests were used for survival analysis. Multivariate analyses were based on the Cox proportional hazards regression model. All statistical tests were two sided, and $\mathrm{P}<0.05$ was considered to indicate a statistically significant difference.

\section{Results}

Immunohistochemical analysis of PD-L1 or PD-1 expression and their association with clinicopathological characteristics. In ECC tissues, immunostaining of PD-L1 was observed in the plasma membrane and cytoplasm of cancer cells and TILs. PD-1 expression was observed in TILs. Representative images are shown in Fig. 1.

The positive rate of PD-L1 expression in bile duct cells of ECC tissues was $42.86 \%$ (30/70), while the positive rate in para-carcinoma tissues was $16.00 \%(8 / 50)$. The difference was statistically significant $(\mathrm{P}=0.002)$. The mean SID score of $\mathrm{PD}-\mathrm{L} 1$ staining was $2.8841 \pm 2.1181$ [mean \pm standard deviation (SD)] in ECC tissues and 1.8400 \pm 2.1346 (mean \pm SD) in para-carcinoma tissues $(\mathrm{P}=0.038)$. The positive rate of PD-L1 expression in TILs of ECC tissues was $37.10 \%$ (26/70). By contrast, only $20.00 \%$ (10/50) of para-carcinoma tissues exhibited positive PD-L1 expression ( $\mathrm{P}=0.043$ ).

Of 70 ECC tissues specimens, 37 cases (52.86\%) demonstrated positive PD-I expression in TILs. The positive rate was significantly different between the ECC tissues and the para-carcinoma tissues $(\mathrm{P}=0.002)$. It was also observed that PD-L1 expression correlated with PD-1 expression $(\mathrm{P}<0.05)$ (Table I). The association between PD-L1 or PD-1 expression and various clinicopathological characteristics of ECC patients is listed in Table II. The results revealed that the expression levels of PD-LI and PD-I were significantly associated with the AJCC TNM stage of disease $(\mathrm{P}<0.05)$ and lymphatic metastasis $(\mathrm{P}<0.05)$. 


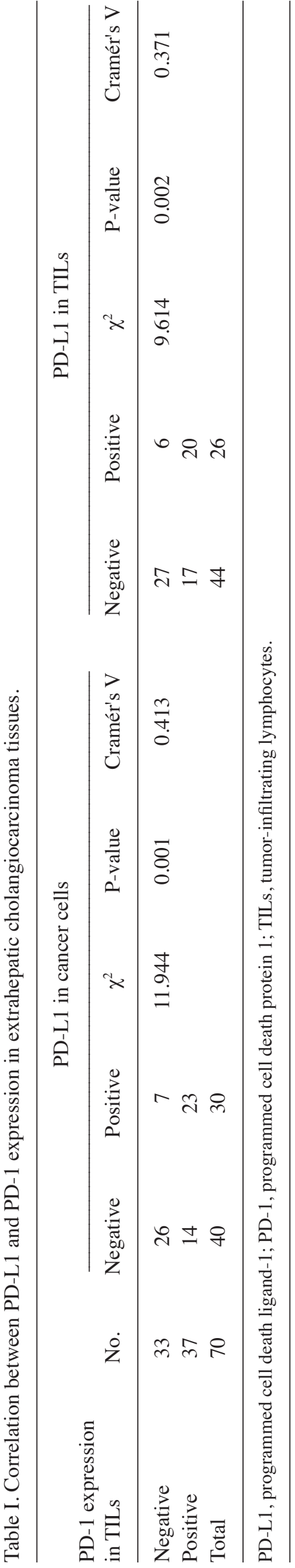

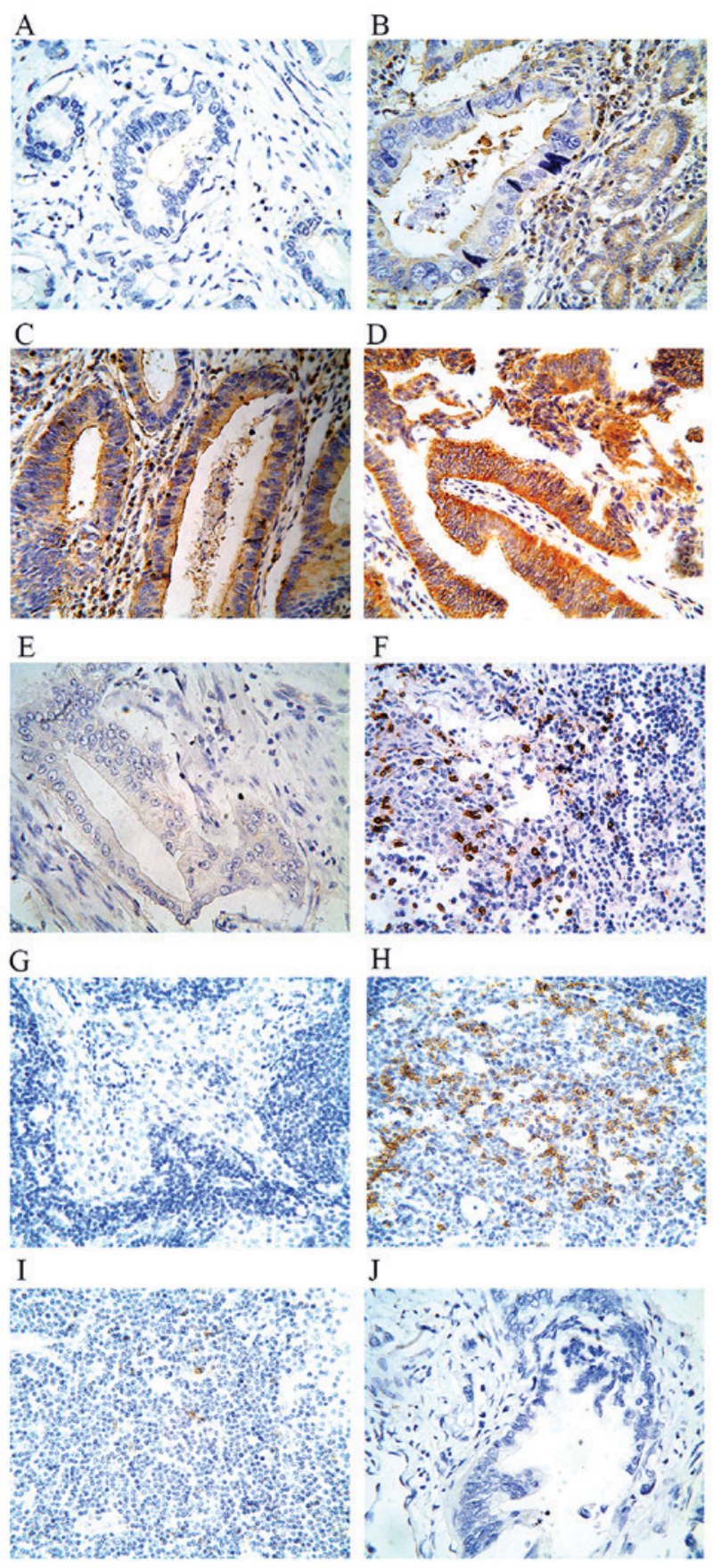

Figure 1. Representative immunohistochemical staining of PD-L1 and PD-1 in ECC and para-carcinoma tissues. (A) Negative, (B) weak, (C) moderate and (D) intense immunostaining for PD-L1 in cancer cells of ECC tissue. (E) Immunostaining for PD-L1 in para-carcinoma tissue. (F) Positive and (G) negative immunostaining for PD-L1 in TILs of ECC tissue. (H) Positive and (I) negative immunostaining for PD-1 in TILs of ECC tissue. (J) Immunostaining for PBS in ECC tissue. Magnification, x400. PD-L1, programmed cell death ligand-1; PD-1, programmed cell death protein 1; TILs, tumor-infiltrating lymphocytes; ECC, extrahepatic cholangiocarcinoma.

Survival analysis for ECC with the Kaplan-Meier method and Cox proportional hazards regression model. Univariate analyses revealed that the overall survival time of ECC patients was significantly associated with PD-L1 or PD-1 expression, TNM stage and lymphatic metastasis (Table III). The Kaplan-Meier survival curves for PD-L1- and PD-1-positive and -negative cases are shown in Fig. 2. The prognostic factors 


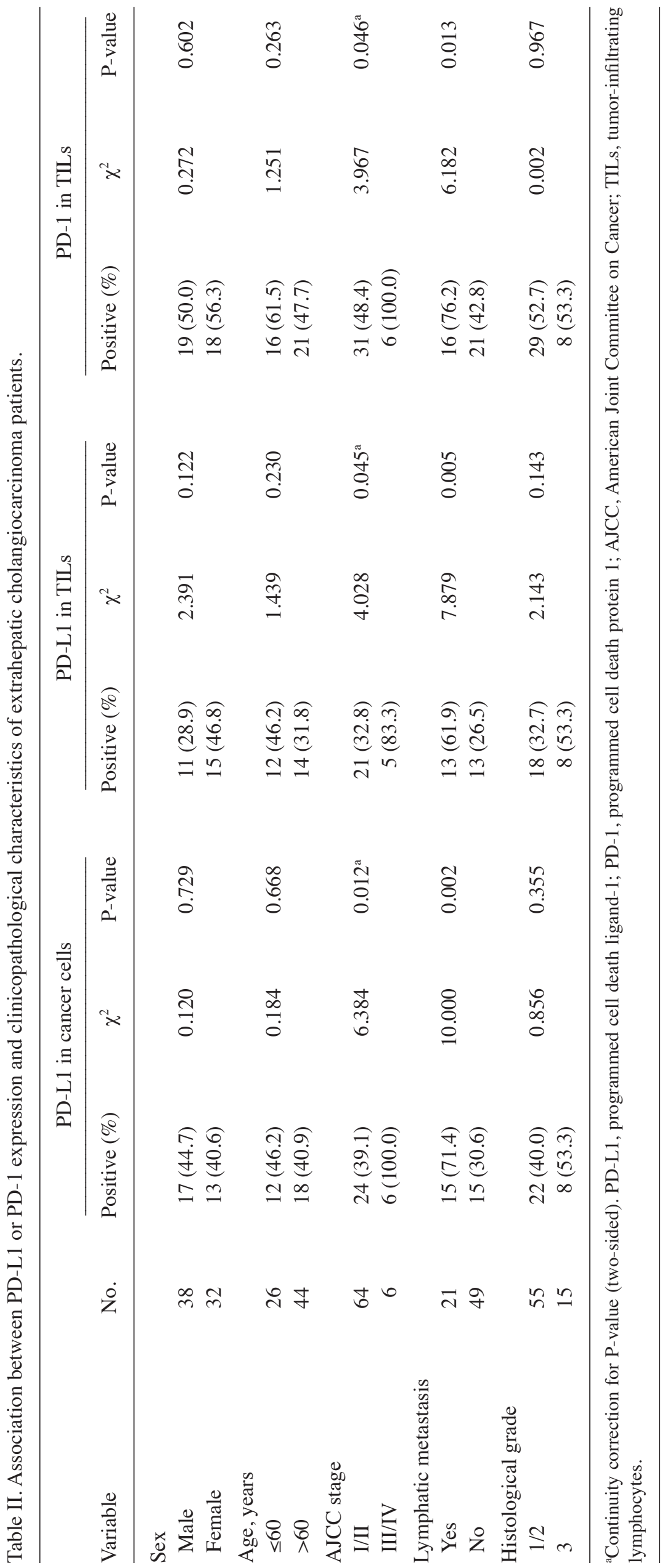


Table III. Univariate analysis of prognosis for extrahepatic cholangiocarcinoma patients $(\mathrm{n}=70)$.

\begin{tabular}{|c|c|c|c|}
\hline Variable & mOS, months & HR (95\% CI) & P-value \\
\hline \multicolumn{4}{|l|}{ Sex } \\
\hline Female vs. male & 25.1 vs. 23.8 & $0.921(0.530-1.600)$ & 0.770 \\
\hline \multicolumn{4}{|l|}{ Age at diagnosis, years } \\
\hline$\leq 60$ vs. $>60$ & 23.1 vs. 29.0 & $0.635(0.362-1.117)$ & 0.111 \\
\hline \multicolumn{4}{|l|}{ AJCC stage } \\
\hline I/II vs. III/IV & 25.5 vs. 19.8 & $2.701(1.109-6.582)$ & 0.022 \\
\hline \multicolumn{4}{|l|}{ Histological grade } \\
\hline $1 / 2$ vs. 3 & 25.0 vs. 22.0 & $1.247(0.662-2.351)$ & 0.491 \\
\hline \multicolumn{4}{|l|}{ Lymphatic metastasis } \\
\hline Yes vs. no & 19.8 vs. 28.0 & $0.507(0.284-0.905)$ & 0.019 \\
\hline \multicolumn{4}{|l|}{ PD-L1 in cancer cells } \\
\hline Positive vs. negative & 19.8 vs. 29.0 & $0.413(0.237-0.719)$ & 0.001 \\
\hline \multicolumn{4}{|l|}{ PD-L1 in TILs } \\
\hline Positive vs. negative & 18.0 vs. 29.4 & $0.424(0.241-0.746)$ & 0.002 \\
\hline \multicolumn{4}{|l|}{ PD-1 in TILs } \\
\hline Positive vs. negative & 21.1 vs. 31.0 & $0.368(0.205-0.659)$ & $<0.001$ \\
\hline
\end{tabular}

AJCC, American Joint Committee on Cancer; PD-L1, programmed cell death ligand-1; PD-1, programmed cell death protein 1; TILs, tumor-infiltrating lymphocytes; mOS, median overall survival; HR, hazard ratio; CI, confidence interval.
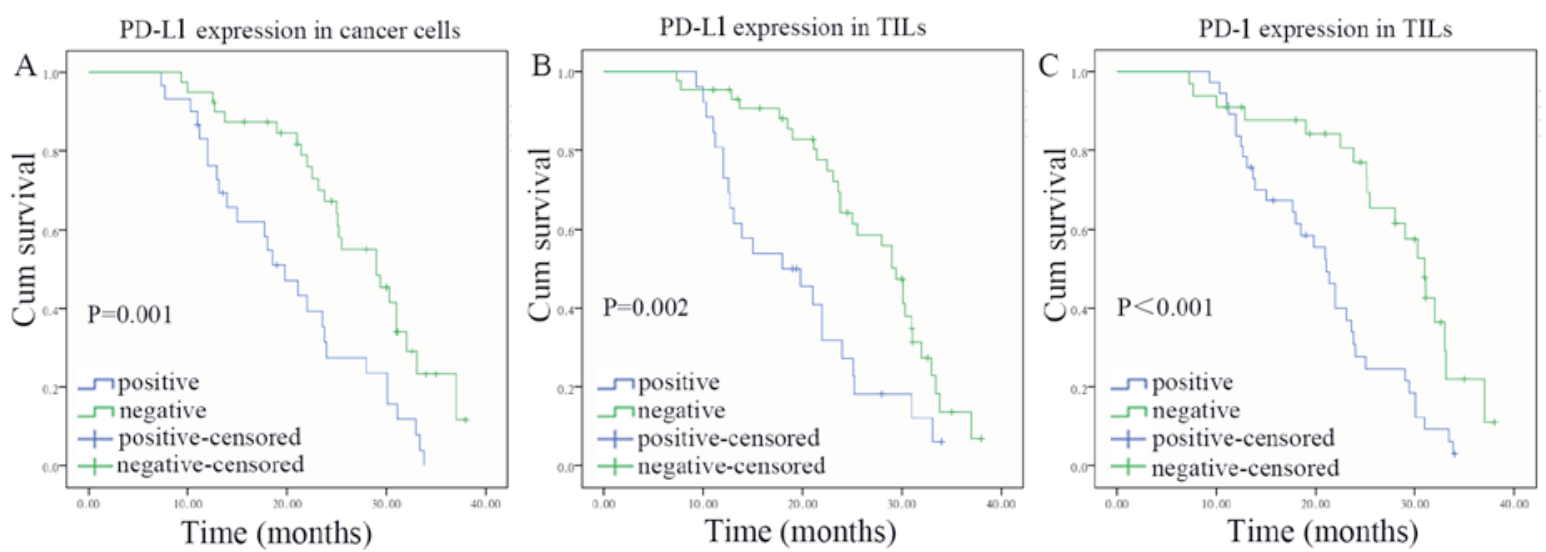

Figure 2. Kaplan-Meier survival curves for 70 patients with ECC grouped according to PD-L1 and PD-1 expression. (A) Negative expression cases of PD-L1 in cancer cells of ECC patients demonstrated a significantly better prognosis than the positive ones ( $\mathrm{P}=0.001)$. (B) Negative expression cases of PD-L1 in TILs of ECC patients demonstrated a significantly better prognosis than the positive ones ( $\mathrm{P}=0.002)$. (C) Negative expression cases of PD-1 in TILs of ECC patients demonstrated a significantly better prognosis than the positive ones ( $\mathrm{P}<0.001)$. PD-L1, programmed cell death ligand-1; PD-1, programmed cell death protein 1; TILs, tumor-infiltrating lymphocytes; ECC, extrahepatic cholangiocarcinoma.

considered significant on univariate analysis were subjected to multivariate analysis using a Cox proportional hazards model. Further multivariate analysis revealed that PD-L1 expression in cancer cells [hazard ratio (HR), 2.314; $95 \%$ confidence interval (CI), 1.129-4.747; $\mathrm{P}=0.022]$ or TILs (HR, 2.468; 95\% CI, 1.229-4.956; $\mathrm{P}=0.011)$ of ECC patients remained independently associated with survival time (Table IV).

\section{Discussion}

In the past two decades, much attention has been paid to PD-L1 and its receptor PD-1 due to their roles in tumor immune evasion and immunotolerance mechanisms (27-29). The activation of the PD-L1/PD-1 pathway can lead to an inhibitory immune tumor microenvironment, which results in the cancer cells evading immune surveillance and destruction (7). On the contrary, blocking this pathway can enhance endogenous antitumor immune effects, which is the theoretical basis of the promising strategy known as immune checkpoint blockade for targeting solid tumors $(4,5)$. Currently, numerous checkpoint inhibitors targeting PD-1 (such as nivolumab and pembrolizumab) and PD-L1 (such as MPDL3280A and BMS-936559) have achieved promising antitumor effects without serious adverse reactions in clinical trials $(31,32,35)$. 
Table IV. Multivariate analysis of prognosis for extrahepatic cholangiocarcinoma patients $(n=70)$.

\begin{tabular}{lcc}
\hline Variable & P-value & HR (95\% CI) \\
\hline AJCC stage & 0.764 & $1.169(0.422-3.236)$ \\
Lymphatic metastasis & 0.959 & $1.016(0.543-1.901)$ \\
PD-L1 in cancer cells & 0.022 & $2.314(1.129-4.747)$ \\
PD-L1 in TILs & 0.011 & $2.468(1.229-4.956)$ \\
PD-1 in TILs & 0.209 & $1.568(0.778-3.160)$ \\
\hline
\end{tabular}

AJCC, American Joint Committee on Cancer; PD-L1, programmed cell death ligand-1; PD-1, programmed cell death protein 1; TILs, tumor-infiltrating lymphocytes; HR, hazard ratio; CI, confidence interval.

Thus, pembrolizumab and nivolumab were approved for the treatment of advanced melanoma and NSCLC by the USA Food and Drug Administration in 2014 and 2015, respectively (36).

Considering the rising morbidity and poor prognosis of ECC as well as the benefits to clinical patients exerted by immune therapies, and with the aim of exploring the feasibility of ECC immunotherapy, the present study detected the expression of PD-L1 and PD-1 by immunohistochemical staining in ECC patients, and further analyzed the association between PD-L1 or PD-1 expression with clinicopathological characteristics, as well as the ability of predicting the prognosis of patients with ECC. The present study provides the first evidence that the positive rate of PD-L1 expression as well as that of its receptor PD-1 in ECC tissues were increased compared with those in para-carcinoma tissues. PD-L1 was highly expressed in both cancer cells and TILs, while PD-1 was highly expressed in TILs of ECC tissues. To better understand the role of PD-L1 expression in ECC patients and the association between PD-L1 and PD1 expression, the significance of PD-L1 expression was separately analyzed according to the expression localization.

Analysis of the associations of PD-L1 or PD-1 expression with ECC clinicopathological characteristics and prognosis revealed that the expression levels of PD-L1 and PD-1 were significantly associated with lymphatic metastasis, tumor stage and overall survival, which suggests that tumor-associated PD-L1 and PD-1 expression may be relevant to tumor progression, and that PD-L1 and PD-1 may be involved in the occurrence and development of ECC. Thus, immunotherapy for ECC patients using monoclonal antibodies against PD-L1 or PD-1 may benefit ECC patients.

The high expression of PD-L1 in different cancers and its clinical significance have been extensively studied, and previous survival analyses demonstrated that PD-L1 was associated with prognosis $(10-12,14,16,17,22)$. The present observations indicated that PD-L1 expression in cancer cells or TILs of ECC patients was significantly correlated with tumor stage and lymphatic metastasis, and that patients with high expression of PD-L1 had a significantly poorer prognosis than those with low expression, which was in line with the results from previous reports on other cancer types (10-12,14,16,17,22). Additionally, Muenst et al (37) explored the expression of PD-1 in TILs on a tissue microarray encompassing 660 breast cancer cases, which revealed that PD-1 was associated with tumor size, grade and lymph node status, and was differentially associated with overall survival. To summarize, the present study demonstrated that PD-L1 or PD-1 immunodetection may be a valuable prognostic marker for ECC patients.

Notably, the present study observed that the expression of PD-L1 exhibited a positive correlation with the expression of PD-1. Besides, tumor-associated PD-LI expression was inversely correlated with cluster of differentiation $8^{+}$TILs $(16,20,21)$. Therefore, it is possible that overexpressed PD-L1 in ECC cancer cells or TILs interacts with PD-1 in TILs, and these interactions may inhibit the functions of $\mathrm{T}$ lymphocytes, resulting in the cancer cells evading immune surveillance and destruction. Of note, this assumption must be further studied, as well as the particular role of PD-LI expression in TILs.

Regarding the regulation of PD-L1 expression, two general mechanisms involving tumor cells have emerged: Innate immune resistance and adaptive immune resistance (5). Certain studies indicated that the phosphoinositide 3-kinase-AKT signaling pathway (38), anaplastic lymphoma kinase signaling (39) and several cytokines $(27,40,41)$ participate in the regulation of PD-L1 expression. However, the specific mechanism of PD-L1 increase in cancer cells and TILs, and of PD-1 increase in TILs of ECC tissues, as well as how their interaction leads to an immune suppressive microenvironment and evasion of immune surveillance, must be further investigated.

Since the present study is a retrospective, small-sample study and sampling differences may influence the result, further prospective, large-sample studies are required to confirm the role of PD-L1 and PD-1 in ECC. Certainly, further investigation regarding the regulation and biological characteristics of PD-L1 and PD-1 will help us to clarify the clinical significance and develop new strategies of tumor immunotherapy. The authors consider that immunotherapy will benefit ECC patients.

\section{References}

1. Nakamura H, Arai Y, Totoki Y, Shirota T, Elzawahry A, Kato M, Hama N, Hosoda F, Urushidate T, Ohashi S, et al: Genomic spectra of biliary tract cancer. Nat Genet 47: 1003-1010, 2015.

2. Aljiffry M, Walsh MJ and Molinari M: Advances in diagnosis, treatment and palliation of cholangiocarcinoma: 1990-2009. World J Gastroenterol 15: 4240-4262, 2009.

3. Murakami Y, Uemura K, Sudo T, Hayashidani Y, Hashimoto Y, Nakamura H, Nakashima A and Sueda T: Adjuvant gemcitabine plus S-1 chemotherapy improves survival after aggressive surgical resection for advanced biliary carcinoma. Ann Surg 250: 950-956, 2009.

4. Bordon Y: Tumour immunology: Checkpoint parley. Nat Rev Immunol 15: 5, 2015.

5. Pardoll DM: The blockade of immune checkpoints in cancer immunotherapy. Nat Rev Cancer 12: 252-264, 2012.

6. Zang X and Allison JP: The B7 family and cancer therapy: Costimulation and coinhibition. Clin Cancer Res 13: 5271-5279, 2007.

7. Zou W and Chen L: Inhibitory B7-family molecules in the tumour microenvironment. Nat Rev Immunol 8: 467-477, 2008.

8. Godwin JL, Zibelman M, Plimack ER and Geynisman DM: Immune checkpoint blockade as a novel immunotherapeutic strategy for renal cell carcinoma: A review of clinical trials. Discov Med 18: 341-350, 2014. 
9. Freeman GJ, Long AJ, Iwai Y, Bourque K, Chernova T, Nishimura H, Fitz LJ, Malenkovich N, Okazaki T, Byrne MC, et al: Engagement of the PD-1 immunoinhibitory receptor by a novel $\mathrm{B} 7$ family member leads to negative regulation of lymphocyte activation. J Exp Med 192: 1027-1034, 2000.

10. Wu C, Zhu Y, Jiang J, Zhao J, Zhang XG and $\mathrm{Xu} \mathrm{N}$ Immunohistochemical localization of programmed death-1 ligand-1 (PD-L1) in gastric carcinoma and its clinical significance. Acta histochem 108: 19-24, 2006.

11. Ghebeh H, Mohammed S, Al-Omair A, Qattan A, Lehe C, Al-Qudaihi G, Elkum N, Alshabanah M, Bin Amer S, Tulbah A, et al: The B7-H1 (PD-L1) T lymphocyte-inhibitory molecule is expressed in breast cancer patients with infiltrating ductal carcinoma: Correlation with important high-risk prognostic factors. Neoplasia 8: 190-198, 2006.

12. Hamanishi J, Mandai M, Iwasaki M, Okazaki T, Tanaka Y, Yamaguchi K, Higuchi T, Yagi H, Takakura K, Minato N, et al: Programmed cell death 1 ligand 1 and tumor-infiltrating CD8+ $\mathrm{T}$ lymphocytes are prognostic factors of human ovarian cancer. Proc Natl Acad Sci USA 104: 3360-3365, 2007.

13. Yang W, Chen PW, Li H, Alizadeh H and Niederkorn JY: PD-L1: PD-1 interaction contributes to the functional suppression of T-cell responses to human uveal melanoma cells in vitro. Invest Ophthalmol Vis Sci 49: 2518-2525, 2008

14. Thompson RH, Kuntz SM, Leibovich BC, Dong H, Lohse CM, Webster WS, Sengupta S, Frank I, Parker AS, Zincke H, et al: Tumor B7-H1 is associated with poor prognosis in renal cell carcinoma patients with long-term follow-up. Cancer Res 66 3381-3385, 2006.

15. Geng L, Huang D, Liu J, Qian Y, Deng J, Li D, Hu Z, Zhang J, Jiang $\mathrm{G}$ and Zheng S: B7-H1 up-regulated expression in human pancreatic carcinoma tissue associates with tumor progression. J Cancer Res Clin Oncol 134: 1021-1027, 2008.

16. Nomi T, Sho M, Akahori T, Hamada K, Kubo A, Kanehiro H, Nakamura S, Enomoto K, Yagita H, Azuma M and Nakajima Y: Clinical significance and therapeutic potential of the programmed death-1 ligand/programmed death-1 pathway in human pancreatic cancer. Clin Cancer Res 13: 2151-2157, 2007.

17. Xylinas E, Robinson BD, Kluth LA, Volkmer BG, Hautmann R, Küfer R, Zerbib M, Kwon E, Thompson RH, Boorjian SA and Shariat SF: Association of T-cell co-regulatory protein expression with clinical outcomes following radical cystectomy for urothelial carcinoma of the bladder. Eur J Surg Oncol 40: 121-127, 2014

18. Nakanishi J, Wada Y, Matsumoto K, Azuma M, Kikuchi K and Ueda S: Overexpression of B7-H1 (PD-L1) significantly associates with tumor grade and postoperative prognosis in human urothelial cancers. Cancer Immunol Immunother 56: 1173-1182, 2007.

19. Inman BA, Sebo TJ, Frigola X, Dong H, Bergstralh EJ, Frank I, Fradet Y, Lacombe L and Kwon ED: PD-L1 (B7-H1) expression by urothelial carcinoma of the bladder and BCG-induced granulomata: Associations with localized stage progression. Cancer 109: 1499-1505, 2007.

20. Konishi J, Yamazaki K, Azuma M, Kinoshita I, Dosaka-Akita H and Nishimura M: B7-H1 expression on non-small cell lung cancer cells and its relationship with tumor-infiltrating lymphocytes and their PD-1 expression. Clin Cancer Res 10: 5094-5100, 2004.

21. Ye Y, Zhou L, Xie X, Jiang G, Xie H and Zheng S: Interaction of B7-H1 on intrahepatic cholangiocarcinoma cells with PD-1 on tumor-infiltrating T cells as a mechanism of immune evasion. J Surg Oncol 100: 500-504, 2009.

22. Ohigashi Y, Sho M, Yamada Y, Tsurui Y, Hamada K, Ikeda N, Mizuno T, Yoriki R, Kashizuka H, Yane K, et al: Clinical significance of programmed death-1 ligand-1 and programmed death-1 ligand-2 expression in human esophageal cancer. Clin Cancer Res 11: 2947-2953, 2005.

23. Zhang Y, Huang S, Gong D, Qin Y and Shen Q: Programmed death-1 upregulation is correlated with dysfunction of tumor-infiltrating CD8+ T lymphocytes in human non-small cell lung cancer. Cell Mol Immunol 7: 389-395, 2010.
24. Lyford-Pike S, Peng S, Young GD, Taube JM, Westra WH, Akpeng B, Bruno TC, Richmon JD, Wang H, Bishop JA, et al: Evidence for a role of the PD-1:PD-L1 pathway in immune resistance of HPV-associated head and neck squamous cell carcinoma. Cancer Res 73: 1733-1741, 2013.

25. Sfanos KS, Bruno TC, Meeker AK, De Marzo AM, Isaacs WB and Drake CG: Human prostate-infiltrating CD8+ T lymphocytes are oligoclonal and PD-1+. Prostate 69: 1694-1703, 2009.

26. Ahmadzadeh M, Johnson LA, Heemskerk B, Wunderlich JR, Dudley ME, White DE and Rosenberg SA: Tumor antigen-specific CD8 T cells infiltrating the tumor express high levels of PD-1 and are functionally impaired. Blood 114: 1537-1544, 2009.

27. Dong H, Strome SE, Salomao DR, Tamura H, Hirano F, Flies DB, Roche PC, Lu J, Zhu G, Tamada K, et al: Tumor-associated B7-H1 promotes T-cell apoptosis: A potential mechanism of immune evasion. Nat Med 8: 793-800, 2002.

28. Blank C, Brown I, Peterson AC, Spiotto M, Iwai Y, Honjo T and Gajewski TF: PD-L1/B7H-1 inhibits the effector phase of tumor rejection by $\mathrm{T}$ cell receptor (TCR) transgenic CD8+ T cells. Cancer Res 64: 1140-1145, 2004.

29. Keir ME, Butte MJ, Freeman GJ and Sharpe AH: PD-1 and its ligands in tolerance and immunity. Annu Rev Immunol 26: 677-704, 2008.

30. Flemming A: Cancer: PD1 makes waves in anticancer immunotherapy. Nat Rev Drug Discov 11: 601, 2012.

31. Topalian SL, Hodi FS, Brahmer JR, Gettinger SN, Smith DC, McDermott DF, Powderly JD, Carvajal RD, Sosman JA, Atkins MB, et al: Safety, activity, and immune correlates of anti-PD-1 antibody in cancer. N Engl J Med 366: 2443-2454, 2012.

32. Brahmer JR, Tykodi SS, Chow LQ, Hwu WJ, Topalian SL, Hwu P, Drake CG, Camacho LH, Kauh J, Odunsi K, et al: Safety and activity of anti-PD-L1 antibody in patients with advanced cancer. N Engl J Med 366: 2455-2465, 2012.

33. Edge SB, Byrd DR, Compton CC, Fritz AG, Greene FL and Trotti A (eds): AJCC Cancer Staging Manual. 7th Edition. Springer, New York, NY, pp66-71, 2010.

34. Al-Shibli K, Al-Saad S, Donnem T, Persson M, Bremnes RM and Busund LT: The prognostic value of intraepithelial and stromal innate immune system cells in non-small cell lung carcinoma. Histopathology 55: 301-312, 2009.

35. Sunshine J and Taube JM: PD-1/PD-L1 inhibitors. Curr Opin Pharmacol 23: 32-38, 2015.

36. Lee J, Kefford R and Carlino M: PD-1 and PD-L1 inhibitors in melanoma treatment: Past success, present application and future challenges. Immunotherapy 8: 733-746, 2016.

37. Muenst S, Soysal SD, Gao F, Obermann EC, Oertli D and Gillanders WE: The presence of programmed death 1 (PD-1)-positive tumor-infiltrating lymphocytes is associated with poor prognosis in human breast cancer. Breast Cancer Res Treat 139: 667-676, 2013.

38. Parsa AT, Waldron JS, Panner A, Crane CA, Parney IF, Barry JJ, Cachola KE, Murray JC, Tihan T, Jensen MC, et al: Loss of tumor suppressor PTEN function increases B7-H1 expression and immunoresistance in glioma. Nat Med 13: 84-88, 2007.

39. Marzec M,Zhang Q, Goradia A, Raghunath PN, Liu X, Paessler M, Wang HY, Wysocka M, Cheng M, Ruggeri BA and Wasik MA: Oncogenic kinase NPM/ALK induces through STAT3 expression of immunosuppressive protein CD274 (PD-L1, B7-H1). Proc Natl Acad Sci USA 105: 20852-20857, 2008.

40. Curiel TJ, Wei S, Dong H, Alvarez X, Cheng P, Mottram P, Krzysiek R, Knutson KL, Daniel B, Zimmermann MC, et al: Blockade of B7-H1 improves myeloid dendritic cell-mediated antitumor immunity. Nat Med 9: 562-567, 2003.

41. Brown JA, Dorfman DM, Ma FR, Sullivan EL, Munoz O, Wood CR, Greenfield EA and Freeman GJ: Blockade of programmed death-1 ligands on dendritic cells enhances $\mathrm{T}$ cell activation and cytokine production. J Immunol 170: 1257-1266, 2003. 